\title{
Analysis of Seven STR Human loci for Paternity Testing by Microchip Electrophoresis
}

\author{
Karina Fraige $^{1}$, Regiane Fátima Travensolo ${ }^{1}$ and Emanuel Carrilho ${ }^{1,2^{*}}$ \\ ${ }^{1}$ Instituto de Química de São Carlos; Universidade de São Paulo; São Carlos - SP - Brasil. ${ }^{2}$ Instituto Nacional de \\ Ciência e Tecnologia de Bioanalítica; Campinas - SP - Brasil
}

\begin{abstract}
The aim of this work was to evaluate two paternity cases by microchip electrophoresis and the validation of the methodology by comparison of the results with those obtained in a commercial genetic analyzer. It was observed that when working with tetranucleotide regions, in which the minimal difference between the alleles was only four base pairs, the commercial microchip system did not present the resolution and repeatability needed. Nevertheless, the relative standard deviation was between 0 and $1.2 \%$ and the fragments detected were within the expected size ranges as described in the literature.
\end{abstract}

Key words: Bioanalyzer 2100, paternity testing, polymerase chain reaction, short tandem repeats

\section{INTRODUCTION}

Paternity testing by DNA analysis is one of the $20^{\text {th }}$ century's most notable advances in the forensic area. The application of DNA typing is increasing in medical laboratories, and one of the most widely used technique is the polymerase chain reaction (PCR) analysis of short tandem repeat (STR) loci (Alford et al. 1994; Sacchetti et al. 1999). The STR loci are polymorphic markers consisting of a variable number of tandem repeats ranging from two to six nucleotides, which are easily amplified by the PCR. They offer a number of advantages over previously used methods, including the ability to obtain results from the degraded samples and extremely small amounts of DNA. Thirteen STR markers were selected in November 1997 to form the core of FBI Laboratory's Combined DNA Index System (CODIS). They are CSF1PO, FGA, TH01, TPOX, VWA, D3S1358, D5S818, D7S820，D8S1179,
D13S317, D16S539, D18S51 and D21S11 loci from the human genome (Butler, 2001).

Amplified STR fragments can be separated and detected by the slab gel electrophoresis. However, capillary electrophoresis (CE) has become increasingly popular for the STR typing and is the method of choice for the analysis of PCR products generated in genotyping tests. The $\mathrm{CE}$ eliminates the need to pour gels and to load the DNA samples onto the gel, apart from the automation and higher efficiency supplied by the available genetic analyzers (Moretti et al. 2001; Butler 2004).

In spite of the numerous advantages of the $\mathrm{CE}$, the equipment for DNA analysis is somewhat expensive, requiring specialized hardware and software, as well as substantial user training and experience; recent advances have allowed the CE to be performed using the microchip devices (Panaro et al. 2000; Kupfer et al. 2006). The ability of the Agilent 2100 Bioanalyzer, a relatively inexpensive and simple to operate

"Author for correspondence: emanuel@iqsc.usp.br 
equipment was evaluated for the paternity test. Consistent results were obtained with respect to the sizing and signal quantification on a well-towell, chip-to-chip, and day-to-day basis, using the PCR fragments and commercially available plasmid digests. Four protocols were used to load the chip wells, with minor modifications of the manufacturer's recommendations. With both, the purified and unpurified PCR products, the relative standard deviation (RSD) for signal quantification was $4.0-5.4 \%$ and for the sizing results, these were lower than $1 \%$ for all the chips, with no results differing from the expected size by more than nine base pair (bp). The cross-contamination between the wells was investigated and no contamination was observed. The ability of sizing the samples with multiple DNA fragments was evaluated by the analysis of commercial plasmid digests, with the RSD for sizing the fragments ranging from $\leq 2.1-8.0 \%$ and for DNA sizing quantification from $\leq 6.7-7.0 \%$. This system was capable of substituting the conventional $\mathrm{CE}$ in sizing and quantification of DNA fragments in many samples (Panaro et al. 2000).

A qualitative method of genotyping involved using the Agilent 2100 Bioanalyzer for the separation of PCR products amplified from STR loci selected from the tetrameric CODIS STR loci and the method was applied to paternity tests. The results were validated in a capillary electrophoresis system and were in agreement in all the cases. This instrument is a rapid and inexpensive alternative for analysis of STR PCR products in comparative analysis, due to the high level of reproducibility of intra-chip and inter-chip sizes; absolute allele identification, however, was not achieved because the resolution of the system was $5 \mathrm{bp}$. The method worked well for the uniplex and multiplex systems, but failed in discriminate tetrameric CSF1PO alleles in which the products were greater than $300 \mathrm{bp}$, suggesting that this locus was less informative for genotyping on the Bioanalyzer because its size range was not within the more selective range of the instrument. It was concluded that the Bioanalyzer was appropriate for the application in small sets of forensic samples, but a large number of them would be more appropriately analyzed by the $\mathrm{CE}$ because of the multiplexed reactions and increased sample capacity (Kupfer et al. 2006).

In this work, the amplification of the DNA by PCR was studied with seven sets of primers corresponding to seven standardized and legally accepted regions in paternity tests (D21S11, Penta E, D18S51, TH01, CSF1PO, D7S820 and D13S317). The extraction of DNA and conditions of PCR reactions were optimized with monitoring by the slab gel electrophoresis. Two paternity cases were evaluated by the microchip electrophoresis in an Agilent 2100 Bioanalyzer with the validation of the method carried out by comparing the results with those from a commercial sequencer (MegaBACE ${ }^{\mathrm{TM}} 500$ Genetic Analyzer).

\section{MATERIALS AND METHODS}

\section{Sampling}

Saliva samples are a potentially useful source of genomic DNA for genetic studies and can be collected in a painless and non-invasive manner ( $\mathrm{Ng}$ et al. 2004). Because of this convenience, saliva was used instead of blood for optimization of DNA extraction and PCR conditions. The samples were obtained from four individuals. Prior to obtaining the samples, the mouth of each individual was rinsed with filtered water for about $10 \mathrm{~s}$ and the water was discarded. After $5 \mathrm{~min}$, the saliva that accumulated in each individual's mouth was collected in sterile polypropylene tubes that were stored at $-20{ }^{\circ} \mathrm{C}$ until DNA extraction. The DNA were obtained from the blood samples in two paternity cases as a donation from the DNA Consult (São Carlos, SP, Brazil), a certified paternity laboratory for case-study comparison.

\section{DNA extraction}

The DNA of saliva was extracted by the phenolchloroform method, according to Walsh et al. (1992), with some modifications. Saliva aliquots of $200 \mu \mathrm{L}$ were transferred to sterile tubes and were centrifuged (Labnet Force 7 Microcentrifuge, Labnet Inc.) at $10,000 \times \mathrm{g}$ for $2 \mathrm{~min}$ and the supernatant was discarded. Lysis buffer $(700 \mu \mathrm{L})$ and proteinase $\mathrm{K}(35 \mu \mathrm{L}$ of $20 \mathrm{mg} / \mathrm{mL})$ were added to the pellet and incubated at $56{ }^{\circ} \mathrm{C}$ in a shaker with temperature controller (Thermomixer Compact, Eppendorf) for about $10 \mathrm{~h}$. After this time, an equal volume of 25:24:1 phenol/chloroform/isoamyl alcohol (v/v/v) was added to the mixture with brief agitation and further centrifuged at $12,000 \times \mathrm{g}$ and $4{ }^{\circ} \mathrm{C}$ for 10 $\mathrm{min}$ in refrigerated microcentrifuge (5415 R, Eppendorf). The layer containing the DNA was 
transferred to a new tube with an equal volume of absolute ethanol $\left(-20{ }^{\circ} \mathrm{C}\right)$, and $80 \mu \mathrm{L}$ of $3 \mathrm{M}$ sodium acetate buffer ( $\mathrm{pH}$ 5.96) were added to precipitate the DNA. The tubes were stored at $-20{ }^{\circ} \mathrm{C}$ for $5 \mathrm{~h}$. After centrifugation at $12,000 \times$ $\mathrm{g}$ and $4{ }^{\circ} \mathrm{C}$ for $10 \mathrm{~min}$, the supernatant was discarded and $50 \mu \mathrm{L}$ sterile water was added to resuspend the pellet. The extraction process was repeated, the pellet was dried in a vacuum centrifuge (Centrivap Concentrator, Labconco Corp.) at $35^{\circ} \mathrm{C}$ for $10 \mathrm{~min}$, re-suspended in $80 \mu \mathrm{L}$ of sterile water and quantified in an UV-Vis U-
2800 spectrophotometer (Hitachi) at $260 \mathrm{~nm}$. The DNA from blood was extracted by DNA Consult personnel with Brazol (LGC Biotecnologia) according to the protocol from the manufacturer.

\section{Amplification of STR loci}

Primers were synthesized by the Erviegas Instrumental Cirúrgico Ltda, according to the sequences described in the literature. The studied loci and their primer sequences are listed in Table 1 .

Table 1 - Characteristics of the studied loci: primer sequences, GenBank accession number, repeat sequence, allele sizes.

\begin{tabular}{|c|c|c|c|c|}
\hline Locus & Primer sequence & $\begin{array}{l}\text { GenBank } \\
\text { accession }\end{array}$ & Repeat sequence & $\begin{array}{l}\text { Allele size } \\
\text { range (bp) }\end{array}$ \\
\hline D21S11 & $\begin{array}{l}\text { A:ATATGTGAGTCAATTCCCCAAG } \\
\text { B:TGTATTAGTCAATGTTCTCCAG }\end{array}$ & M84567 & $\begin{array}{l}(\text { TCTA })_{n}(\text { TCTG })_{n} \\
\text { [(TCTA)3TA(TCTA)3 } \\
\text { TCA }(\text { TCTA }) 2 \text { TCCAT } \\
\text { A] }(\text { TCTA })_{n} \text { - complex }\end{array}$ & $214-240$ \\
\hline Penta E & $\begin{array}{l}\text { A:GATCAAGACCAGCCTGGGCA } \\
\text { B:TGGGTTATTAATTGAGAAAACTCC } \\
\text { TTACAATTT }\end{array}$ & $\mathrm{AC} 027004$ & AAAGA & $260-300$ \\
\hline D18S51 & $\begin{array}{l}\text { A:CAAACCCGACTACCAGCAAC } \\
\text { B:GAGCCATGTTCATGCCACTG }\end{array}$ & L18333 & $(\mathrm{AGAA})_{\mathrm{n}}$ & $274-318$ \\
\hline TH01 & $\begin{array}{l}\text { A:GTGGGCTGAAAAGCTCCCGATTAT } \\
\text { B:GTGATTCCCATTGGCCTGTTCCTC }\end{array}$ & D00269 & $(\mathrm{AATG})_{\mathrm{n}}$ & $154-178$ \\
\hline CSF1PO & $\begin{array}{l}\text { A:AACCTGAGTCTGCCAAGGACTAGC } \\
\text { B:TTCCACACACCACTGGCCATCTTC }\end{array}$ & X14720 & $(\mathrm{AGAT})_{\mathrm{n}}$ & $299-323$ \\
\hline D7S820 & $\begin{array}{l}\text { A:TGTCATAGTTTAGAACGAACTAAC } \\
\text { G } \\
\text { B:CTGAGGTATCAAAAACTCAGAGG }\end{array}$ & G08616 & (GATA)n & $198-222$ \\
\hline D13S317 & $\begin{array}{l}\text { A:GTTGCTGGACATGGTATCACAG } \\
\text { B:TCAGAGAGCTTGAATTGTTGGT }\end{array}$ & AF25087 & (GATA)n & $245-261$ \\
\hline
\end{tabular}

Six of them were from the 13 CODIS core STR loci and one, Penta E, was discovered and characterized by the Promega scientists in an effort to find a locus with high variability and a low amount of stutter product formation (Bacher and Schumm 1998; Schumm and Bacher 2001) and although not officially required, it has been widely used in the commercial STR kits.

Preliminary testing was performed to optimize the reactions for the primers and template concentration. The conditions selected for the study were $80 \mathrm{ng}$ template DNA in $10 \times$ buffer (Invitrogen), $2 \mathrm{mM} \mathrm{MgCl}$ (Invitrogen), $10 \mathrm{mM}$ dNTP, 1 U of Platinum Taq DNA polymerase (Invitrogen) and 2 pmol of each primer to a final volume of $20 \mu \mathrm{L}$. The final concentration of primers varied from 2 to $10 \mathrm{pmol}$, and the best amplification condition for all the primers was 2 pmol, which minimized the consumption of reagents and formation of primer-dimmers. The following conditions were used in a PTC-100 Programmable Thermal Controller (Eppendorf): 
$95{ }^{\circ} \mathrm{C}$ for $10 \mathrm{~min}, 94{ }^{\circ} \mathrm{C}$ for $1 \mathrm{~min}$, optimized annealing temperature for each primer pair for 1 min, $72{ }^{\circ} \mathrm{C}$ for $1 \mathrm{~min}$ for 34 cycles, with a final extension at $72{ }^{\circ} \mathrm{C}$ for $30 \mathrm{~min}$.

The amplifications of K562 control DNA (Promega) were made with each primer according to the optimized PCR protocol. All the products were analyzed by electrophoresis in $2 \%(\mathrm{w} / \mathrm{v})$ agarose gel in $1 \times \mathrm{TAE}$ buffer containing 0.5 $\mu \mathrm{g} / \mathrm{mL}$ ethidium bromide for the quality control. The sizes of the amplicons were compared with a 25 bp DNA ladder (Invitrogen). The fragments obtained with the best conditions were analyzed in microchip electrophoresis in the Bioanalyzer 2100 (Agilent Technologies).

\section{Microchip and capillary electrophoresis}

The analysis of a 1- $\mu \mathrm{L}$ aliquot of each amplification product was performed by the microchip electrophorersis, in a 2100 Bioanalyzer using Agilent biosizing ${ }^{\mathrm{TM}}$ software (Version A.02.12) and DNA 1000 Labchip $^{\mathrm{TM}}$ kits (Agilent Technologies). This equipment sizes and quantifies 12 samples on a disposable microchip in approximately $30 \mathrm{~min}$. Each glass microchip held 16 wells: three for loading the gel-dye mixture, 12 for the samples and one for a molecular size ladder (Panaro et al. 2000; Funnes-Huacca et al. 2004). The gel-dye mixture consists of a linear polymer and a fluorescent intercalating dye. The marker mixture consists of a buffer with lower and upper molecular size markers, which the software uses as reference for sizing the fragments (Funnes-Huacca et al. 2004). The chips were prepared according to the manufacturer's instructions: the microchannels were filled pipetting $9 \mu \mathrm{L}$ of the gel-dye mixture into the appropriate well and then pressure was applied. Two additional wells were filled with 9 $\mu \mathrm{L}$ gel-dye mixture. The sample and ladder wells were filled with $5 \mu \mathrm{L}$ marker mixture before adding $1 \mu \mathrm{L}$ of DNA ladder or sample to the their wells. The chip was vortexed and placed in the equipment for the analysis. The Bioanalyzer displays data as both the migration time plots and virtual gels are generated by the computer. The temperature, voltage, $\mathrm{pH}$ and buffer properties were automatically set by the instrument and were not varied. The repeatability of sizing each fragment from different wells was evaluated using a 25 bp DNA ladder (Invitrogen), and each sample was analyzed in triplicate. The results were compared with those resulting from the capillary electrophoresis, supplied by the certified laboratory, which was performed in a MegaBACE ${ }^{\mathrm{TM}} 500$ Genetic Analyzer (GE Healthcare). The amplification and labeling of the PCR products for capillary electrophoresis were done using the PowerPlex ${ }^{\mathrm{TM}} 16$ System (Promega). The analyses were made according to the manufacturer's method and the data were treated by the MegaBACE Genetic Profiler ${ }^{\mathrm{TM}}$ software, which indicated the size of each fragment and the corresponding allele. Both the methods, i.e., the primer system and the certified method produced the fragments of different sizes because the primer sequences of the PowerPlex ${ }^{\mathrm{TM}}$ 16 System were not the same as the primers used. The sizes were, however in accordance with those found in the literature based on the position of priming.

\section{RESULTS AND DISCUSSION}

\section{Optimization of PCR conditions}

The phenol-chloroform method used for the extraction of DNA from the saliva yielded the samples with high purity and concentrations, although some modifications of the original protocol, such as reduction in incubation times, were required. Each extraction was performed in duplicates.

PCR is currently recognized as a method of choice for the paternity testing because it requires small amounts of starting DNA template, is highly reproducible, and is relatively insensitive to the degradation for the amplicon sizes. PCR, thus, provides a reliable and independent method to confirm the identification of the sample (Kupfer et al. 2006). The conditions for the PCR were optimized using the DNA from the saliva samples, and the same conditions were applied to the DNA extracted from the blood samples, supplied by a certified paternity laboratory, yielding the same results, i.e., i) good quality of DNA extracted, and ii) optimized PCR cycling conditions.

Typical conditions for the denaturation are $95{ }^{\circ} \mathrm{C}$ from $30 \mathrm{~s}$ or $97{ }^{\circ} \mathrm{C}$ for $15 \mathrm{~s}$ (Innis et al. 1990). In our work, however, we used $94{ }^{\circ} \mathrm{C}$ for $1 \mathrm{~min}$, based on the literature data (Nutini et al. 2003; Ricci et al. 2003), which also provided good results. The annealing temperature for each pair of primers was defined according to melting temperature $(\mathrm{Tm})$ specified by the supplier. The annealing temperature is an important parameter for the success of the amplification because it 
influences the specificity (template sequence) and stability of DNA-DNA hydrogen bonds. Four temperatures around these values were studied as presented in Table 2, which was possible because of the use of a temperature gradient thermocycler. The conditions were evaluated in agarose gel electrophoresis prior to the analysis in the Bioanalyzer (data not shown).

Table 2 - Melting and annealing temperatures used for each primer pair.

\begin{tabular}{ccccc}
\hline Primer & Tm $\left({ }^{\circ} \boldsymbol{C}\right)$ & Mean temperature $\left({ }^{\circ} \mathbf{C}\right)$ & Studied temperatures $\left({ }^{\circ} \boldsymbol{C}\right)$ & Annealing temperature $\left({ }^{\circ} \mathbf{C}\right)$ \\
\hline D21S11 A & 52.0 & 49.0 & $50.0 ; 50.3 ; 51.4 ; 53.2$ & 53.2 \\
D21S11 B & 46.0 & & & \\
Penta E A & 59.4 & 60.1 & $58.1 ; 60.8 ; 63.5 ; 66.0$ & 60.8 \\
Penta E B & 60.8 & & & \\
D18S51 A & 54.3 & 55.2 & $53.2 ; 55.5 ; 58.1 ; 60.8$ & 58.1 \\
D18S51 B & 56.0 & & & \\
TH01 A & 62.2 & 62.8 & $58.1 ; 60.8 ; 63.5 ; 66.0$ & 60.8 \\
TH01 B & 63.4 & & & \\
CSF1PO A & 58.9 & 61.3 & $55.5 ; 58.1 ; 60.8 ; 63.5$ & 55.5 \\
CSF1PO B & 63.7 & & & \\
D7S820 A & 51.7 & 51.5 & $50.3 ; 51.4 ; 53.2 ; 55.5$ & 53.2 \\
D7S820 B & 51.4 & & & \\
D13S317 A & 54.1 & 53.5 & $50.3 ; 51.4 ; 53.2 ; 55.5$ & \\
D13S317 B & 52.9 & & & \\
\hline
\end{tabular}

All the temperatures tested provided an amplification of DNA for all the primers in this study. The annealing temperatures were chosen so that no (or minimal) bands of primer-dimmer were present, or the amplification yielded were pure bands. At lower temperatures, the formation of dimmers could be observed for D21S11 and D18S51. For Penta E, the separation of the fragments into two bands was observed. The same was observed for the CSF1PO at $55.5{ }^{\circ} \mathrm{C}$, a fact not observed at lower temperatures and typical of heterozygote individuals. The comparison of the 25 bp DNA ladder with the produced amplicons indicated that the sizes of these PCR products were in accordance with the expected values.

\section{Microchip electrophoresis}

An Agilent 2100 Bioanalyzer was used for the electrophoresis and analysis of the PCR samples as a less expensive and faster alternative to the capillary electrophoresis genetic analyzer systems used in the paternity testing. In this study, the performance of the instrument to separate six tetranucleotide STR PCR products and one pentanucleotide PCR product (all without any purification process before the analysis) was tested. The kit used in this study was the DNA 1000 Labchip $^{\mathrm{TM}}$ because of its $15-1500 \mathrm{bp}$ range, the minimum available for the manufacturer, was suitable for the PCR fragments. However, the certified resolution was five basepairs, when at least four should be desirable because of the tetrameric alleles. The repeatability of fragment sizing for this instrument was evaluated by the analysis of a commercial $25 \mathrm{bp}$ DNA ladder containing 11 fragments. Table 3 presents the results obtained for each control, as well as the expected size of each fragment, and the values of relative standard deviation (RSD). The RSD of the well-to-well sizing values for the replicates of the 25 bp DNA ladder ranged from 3.0 to $4.3 \%$ over three replicates in a single chip, and the differences between the expected and the obtained values were from 0.4 and $3.5 \%$, indicating good reproducibility and accuracy. The results showed that for larger fragments, the values of the size decreased from first to last wells, which could be observed in the well 12, the last analyzed. Results from the wells 4 and 8 presented higher values than expected, while the well 12 presented lower values than expected.

The RSD of $4.3 \%$ was not significant when evaluated for $50 \mathrm{bp}$ fragments, but became significant as the size of the fragment increased. The optimized PCR conditions were applied to the amplification of K562 DNA control along with the 
seven pairs of primers and analyzed by the microchip electrophoresis. Results of sizing from the microchip electrophoresis were compared with those obtained in the capillary electrophoresis for allelic standards and for two authentic paternity cases. The number of each allele was correlated by the MegaBACE software (Table 4).

Table 3 - Assessing sizing accuracy and precision for fragments 50 - 350 bp of a 25 bp DNA ladder in three different wells of a chip.

\begin{tabular}{|c|c|c|c|c|c|c|}
\hline \multirow{2}{*}{$\begin{array}{l}\text { Size } \\
\text { (bp) }\end{array}$} & \multicolumn{3}{|c|}{ Well \# } & \multirow{2}{*}{$\begin{array}{c}\text { Mean } \\
\text { (bp) }\end{array}$} & \multirow{2}{*}{$\begin{array}{l}\text { RSD } \\
(\%)\end{array}$} & \multirow{2}{*}{$\begin{array}{c}\text { Error } \\
\text { (\%) }\end{array}$} \\
\hline & 4 & 8 & 12 & & & \\
\hline 50 & 52 & 52 & 49 & 51 & 3.4 & 2.0 \\
\hline 75 & 79 & 79 & 75 & 78 & 3.0 & 3.5 \\
\hline 100 & 104 & 104 & 98 & 102 & 3.4 & 2.0 \\
\hline 125 & 131 & 129 & 122 & 127 & 3.7 & 1.9 \\
\hline 150 & 155 & 153 & 144 & 151 & 3.9 & 0.4 \\
\hline 175 & 182 & 180 & 168 & 177 & 4.3 & 0.9 \\
\hline 200 & 208 & 206 & 193 & 202 & 4.0 & 1.2 \\
\hline 225 & 235 & 232 & 218 & 228 & 4.0 & 1.5 \\
\hline 250 & 260 & 257 & 242 & 253 & 3.8 & 1.2 \\
\hline 275 & 286 & 283 & 266 & 278 & 3.9 & 1.2 \\
\hline 300 & 311 & 307 & 289 & 302 & 3.9 & 0.8 \\
\hline 325 & 338 & 334 & 313 & 328 & 4.1 & 1.0 \\
\hline 350 & 364 & 360 & 339 & 354 & 3.8 & 1.2 \\
\hline
\end{tabular}

Table 4 - Correlation of fragment sizing in basepairs (bp) from Bioanalyzer 2100 and from MegaBACE 500, and allele number (al) from MegaBACE 500, for K562 DNA control.

\begin{tabular}{cccc}
\hline \multirow{2}{*}{ Locus } & Bioanalyzer 2100 & \multicolumn{2}{c}{ MegaBACE 500 } \\
\cline { 2 - 4 } & Basepairs (bp) & Bases (b) & Allele (al) \\
\hline D21S11 & 240 & 224 & 29 \\
& 244 & 228 & 30 \\
Penta E & 248 & 232 & 31 \\
& 256 & 382 & 5 \\
D18S51 & 292 & 428 & 14 \\
& 285 & 314 & 15 \\
TH01 & 297 & 318 & 16 \\
CSF1PO & 179 & 181 & 9.3 \\
D7S820 & 318 & 334 & 9 \\
& 219 & 338 & 10 \\
D13S317 & 228 & 230 & 9 \\
& 256 & 238 & 8
\end{tabular}

As expected, the sizes of the amplicons determined by both platforms were different because the pairs of the primers used in this comparison were not the same. Additionally, the DNA molecules run in denatured single-stranded form (ssDNA) in MegaBACE and native doublestranded form (dsDNA) in the Bioanalyzer. When DNA was separated in its single standard form, an increase in the selectivity and resolution was observed compared to the separation of that sample in its double stranded form (van der Schans et al. 1997). The sizes however, were in accordance with those found in the literature based on the sequence, and with the allele numbers attributed by the MegaBACE software. Therefore, this correspondence was made to conduct the paternity cases. For the CSF1PO, the microchip data presented only one fragment, while the capillary electrophoresis presented two. Alleles 9 and 10 for this locus were not resolved sufficiently 
to be distinguished by the Bioanalyzer software. According to Kupfer et al. (2006), the poor resolution of these alleles was probably due to the larger sizes of the CSF1PO PCR products. Moreover, it could be attributed to the fact that the resolution of Bioanalyzer 2100 was $5 \mathrm{bp}$, which was limiting for adequate separation of the fragments differing by only one allele in this case, i.e., a difference of $4 \mathrm{bp}$.

The results of two paternity cases were also obtained in the microchip and capillary electrophoresis, with the PCR conditions described previously, and compared in Table 5. Similar to the analysis of K562 control DNA, there were the cases in which only one fragment was quantified by the microchip software, while two were quantified in the capillary electrophoresis owing to the lack of the resolution. Similar results were observed for the CSF1PO in K562 control and for the alleles with smaller fragments, indicating poor resolution for the fragments differing by one allele independent of the size of the fragments.

Table 5 - Results of fragment sizing in two paternity cases in microchip electrophoresis (base pairs - bp) and capillary electrophoresis (bp and allele - al).

\begin{tabular}{|c|c|c|c|c|c|c|c|c|c|}
\hline \multicolumn{10}{|c|}{ Paternity Case \#1 } \\
\hline \multirow[t]{2}{*}{ Locus } & \multicolumn{3}{|c|}{ Microchip electrophoresis } & \multicolumn{6}{|c|}{ Capillary electrophoresis } \\
\hline & AF (bp) & $\mathrm{C}(\mathbf{b p})$ & M (bp) & AF (bp) & $\mathbf{A F}(\mathbf{a l})$ & $\mathrm{C}(\mathbf{b p})$ & $\mathrm{C}$ (al) & M (bp) & M (al) \\
\hline \multirow{2}{*}{ D21S11 } & 238 & 238 & 240 & 221 & 28 & 221 & 28 & 225 & 29 \\
\hline & 241 & 241 & 243 & 225 & 29 & 225 & 29 & 228 & 30 \\
\hline \multirow[t]{2}{*}{ Penta E } & 272 & 288 & 270 & 398 & 9 & 418 & 12 & 393 & 7 \\
\hline & 288 & 296 & 297 & 418 & 12 & 428 & 14 & 428 & 14 \\
\hline \multirow[t]{2}{*}{ D18S51 } & 283 & 284 & 285 & 308 & 13 & 312 & 14 & 312 & 14 \\
\hline & & & & 312 & 14 & & & 316 & 15 \\
\hline \multirow[t]{2}{*}{ TH01 } & 164 & 163 & 162 & 166 & 6 & 166 & 6 & 166 & 6 \\
\hline & 178 & 177 & 171 & 182 & 9.3 & 182 & 9.3 & 174 & 8 \\
\hline \multirow[t]{2}{*}{ CSF1PO } & 316 & 315 & 316 & 338 & 10 & 338 & 10 & 338 & 10 \\
\hline & 324 & 324 & & 346 & 12 & 346 & 12 & & \\
\hline \multirow{2}{*}{ D7S820 } & 218 & 222 & 222 & 231 & 9 & 235 & 10 & 235 & 10 \\
\hline & 236 & 235 & & 247 & 13 & 247 & 13 & & \\
\hline \multirow[t]{2}{*}{ D13S317 } & 270 & 268 & 267 & 198 & 12 & 198 & 12 & 170 & 6 \\
\hline & & & 274 & & & & & 198 & 12 \\
\hline \multicolumn{10}{|c|}{ Paternity Case \#2 } \\
\hline \multirow[t]{2}{*}{ Locus } & \multicolumn{3}{|c|}{ Microchip electrophoresis } & \multicolumn{6}{|c|}{ Capillary electrophoresis } \\
\hline & AF (bp) & C (bp) & M (bp) & AF (bp) & $\mathbf{A F}(\mathbf{a l})$ & C (bp) & $\mathrm{C}(\mathrm{al})$ & M (bp) & M (al) \\
\hline \multirow[t]{2}{*}{ D21S11 } & 240 & 244 & 242 & 225 & 29 & 229 & 30 & 225 & 29 \\
\hline & 261 & 261 & & 242 & 33.2 & 242 & 33.2 & 228 & 30 \\
\hline \multirow[t]{2}{*}{ Penta E } & 258 & 258 & 296 & 383 & 5 & 383 & 5 & 428 & 14 \\
\hline & 267 & 293 & & 393 & 7 & 428 & 14 & 433 & 15 \\
\hline \multirow[t]{2}{*}{ D18S51 } & 273 & 292 & 293 & 304 & 12 & 328 & 18 & 328 & 18 \\
\hline & 291 & 302 & 302 & 328 & 18 & 340 & 21 & 340 & 21 \\
\hline \multirow[t]{2}{*}{ TH01 } & 166 & 166 & 165 & 166 & 6 & 166 & 6 & 166 & 6 \\
\hline & & & & 170 & 7 & 170 & 7 & 170 & 7 \\
\hline \multirow[t]{2}{*}{ CSF1PO } & 317 & 317 & 323 & 338 & 10 & 338 & 10 & 342 & 11 \\
\hline & 326 & 325 & & 346 & 12 & 346 & 12 & 346 & 12 \\
\hline \multirow[t]{2}{*}{ D7S820 } & 222 & 222 & 222 & 231 & 9 & 231 & 9 & 231 & 9 \\
\hline & 234 & 226 & 226 & 243 & 12 & 235 & 10 & 235 & 10 \\
\hline \multirow[t]{2}{*}{ D13S317 } & 270 & 273 & 273 & 194 & 11 & 198 & 12 & 198 & 12 \\
\hline & 273 & & & 198 & 12 & & & & \\
\hline
\end{tabular}

AF: alleged father; C: children; M: mother 
The electropherograms produced by the separation of loci TH01 and D21S11 in one paternity case are presented in Figure 1. They were overlapped for the ease of visualization of the corresponding bands from the child and those that were inherited from each parent. The manual examination of TH01 electropherograms showed resolved doublets for each individual (alleged father, child, and mother), allowing the fragment sizing and comparison, attributing the paternity to this alleged father. The electropherograms of D21S11, however, showed partially resolved doublets, making the fragment sizing and the comparison among the individuals more difficult, i.e., the paternity investigation. Nevertheless, the Bioanalyzer could be more assertively used for the elimination of the paternity, if a different allele peak was detected among the three samples. Such event was statistically favored if large number of loci was used. The composition of the alleles from the son/daughter in a paternity case functions as leverage since each pair of the bands must be present; one comes from the mother and other comes from the father. The situation is different when applied to the personal identification, such as in the forensic cases, since there is no double point for the comparison.
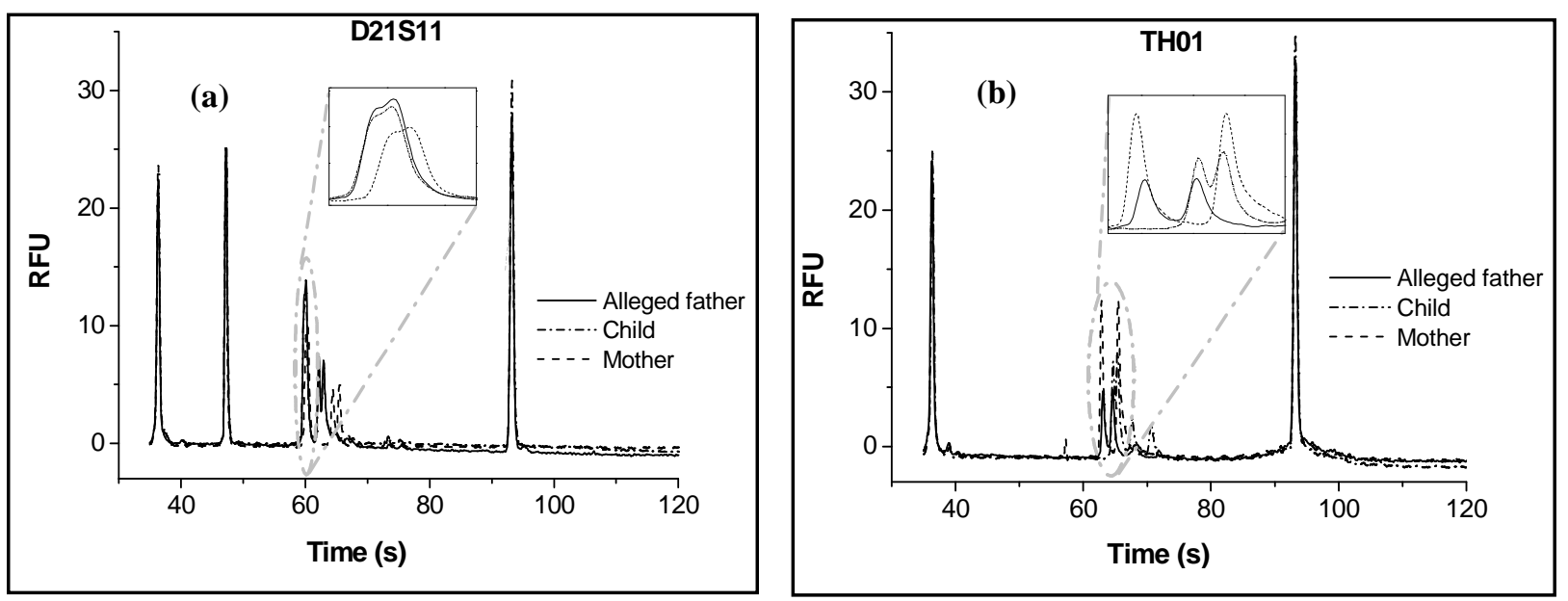

Figure 1 - Overlays of electropherograms of loci D21S11 (a) and TH01 (b) for paternity case \# 1. PCR was performed using conditions described in the text with sample of alleged father, mother, and child. The data analysis was carried out in Bionalyzer software. The sizes of the TH01 suggest an inclusion of paternity while the D21S11 showed partially resolved doublets, which makes fragment sizing and comparison between individuals difficult.

Considering the result of capillary electrophoresis for the seven analyzed loci, it was possible to include the alleged father as the father of the children in two cases, with $99.981 \%$ and $99.993 \%$ for the case 1 and 2, respectively. However, at least twelve loci have been investigated in order to validate these results legally.

In this work, the PCR conditions for the DNA amplification were optimized and established for seven STR loci used in the paternity tests. An evaluation of the conditions studied was analyzed by agarose gel electrophoresis and the best conditions were applied to the analysis of PCR products by the microchip electrophoresis, which was used to evaluate two paternity cases. The results were compared with those obtained in a dedicated genetic analyzer. Although the fragment sizing presented results in the expected ranges, the Bioanalyzer did not present the necessary accuracy and resolution for the genotype testing when the tetranucleotide regions were being investigated. This limitation was intrinsically associated with the lower separation resolution for the double stranded DNA molecules. The RSD for the sizing was below $1.2 \%$, which could be tolerated in many cases, but was restrictive for the analysis of tetranucleotide region. For example, such value suggested errors of $4 \mathrm{bp}$, which could erroneously, exclude or include an individual as a father by one allele difference. The analysis, however, did not 
rely solely on the results of a single allele and the final score was accounted for all the alleles. In order to improve the reliability of the commercial microchip electrophoresis for paternity testing, new primers and, ultimately, new allelic fragment sizes, should be designed.

The use of the Bioanalyzer for positive indication of paternity or identification of the individuals requires an extensive data analysis and knowledge-based obtained with the typical behavior of each allele throughout the separation range. The lack of resolution has to be taken into account in the probabilistic analysis with weighing for the possibility of identity and possibility of $\mathrm{n} \pm$ 1 allele, i.e., the non-resolution of a onetetranucleotide difference. For the exclusion of paternity, whoever, the method could be capable statistically of providing enough resolution to eliminate unequivocally one individual.

\section{ACKNOWLEDGEMENTS}

The authors would like to thank the FAPESP (Fundação de Amparo à Pesquisa do Estado de São Paulo) for the financial support, DNA Consult for the donation of samples and results, and Agilent Technologies for the donation of the Bioanalyzer 2100.

\section{REFERENCES}

Alford RL, Hammond HA, Coto I, Caskey CT. Rapid and efficient resolution of parentage by amplification of short tandem repeats. Am J Hum Genet. 1994; 55: 190-5.

Bacher J, Schumm JW. Profiles in DNA, Promega Corporation. Wisconsin: Madison; 1998.

Butler JM. Forensic DNA Typing: Biology and Technology behind STR markers. London: Academic Press; 2001.

Butler JM., Buel E, Crivallente F, McCord BR. Forensic DNA typing by capillary electrophoresis using the ABI Prism 310 and 3100 genetic analyzers for STR analysis. Electrophoresis. 2004; 25: $1397-$ 1412.

Funes-Huacca ME, Regitano LCA, Mueller O, Carrilho E. Semiquantitative determination of Alicyclobacillus acidoterrestris in orange juice by reversetranscriptase polymerase chain reaction and capillary electrophoresis - laser induced fluorescence using microchip technology. Electrophoresis. 2004; 25: 3860-64.
Innis MA, Gelfand DH, Sninsky JJM, Whiti TJ. PCR protocols: a guide to methods and applications. San Diego: Academic Press; 1990.

Kupfer DM, Huggins M, Cassidy B, Vu N. A Rapid and Inexpensive PCR-Based STR Genotyping Method for Identifying Forensic Specimens, Final Report DOT/FAA/AM-06/14; 2006. Available from: http://www.faa.gov/library/reports/medical/oamtechre ports/index.cfm

Moretti TR, Baumstark AL, Defenbaugh DA, Keys KM, Smerick JB, Budowle B. Validation of short tandem repeats (STRs) for forensic usage: performance testing of fluorescent multiplex STR systems and analysis of authentic and simulated forensic samples. J Forensic Sci. 2001; 46: 647-60.

$\mathrm{Ng}$ DPK, Koh D, Choo SGL, Ng V, Fu Q. Effect of storage conditions on the extraction of PCR-quality genomic DNA from saliva. Clin Chim Acta, 2004; 343: 191-4.

Nutini AL, Mariottini A, Giunti L, Torricelli F, Ricci U. Double incompatibility at human alpha fibrinogen and penta $\mathrm{E}$ loci in paternity testing. Croat Med J. 2003; 44: 342-6.

Panaro NJ, Yuen PK, Sakazume T, Fortina P, Kricka LJ, Wilding P. Evaluation of DNA fragment sizing and quantification by the Agilent 2100 Bioanalyzer. Clin Chem. 2000; 46: 1851-53.

Ricci U, Sani I, Klintschar M, Cerri N, De Ferrari F, Uzielli MLG. Identification of forensic samples by using an infrared-based automatic DNA sequencer. Croat Med J. 2003; 44: 299-305.

Sacchetti L, Calcagno G, Coto I, Tinto N, Vuttariello E, Salvatore F. Efficiency of two different nine-loci short tandem repeat systems for DNA typing purposes. Clin Chem. 1999; 45: 178-83.

Schumm JW, Bacher JW. Materials and methods for identifying and analyzing intermediate tandem repeat DNA markers. U.S. Patent 6,238,863; 2001.

van der Schans MJ, Kuypers AWHM, Kloosterman AD, Janssen HJT, Everaerts FM. Comparison of resolution of double-stranded and single-stranded DNA in capillary electrophoresis. $J$ Chromatogr $A$. 1997; 772: 255-64.

Walsh DJ, Corey AC, Cotton RW, Forman L, Herrin GL, Word CJ, Garner DD. Isolation of deoxyribonucleic acid (DNA) from saliva and forensic science samples containing saliva. $J$ Forensic Sci. 1992; 37: 387-95. 
